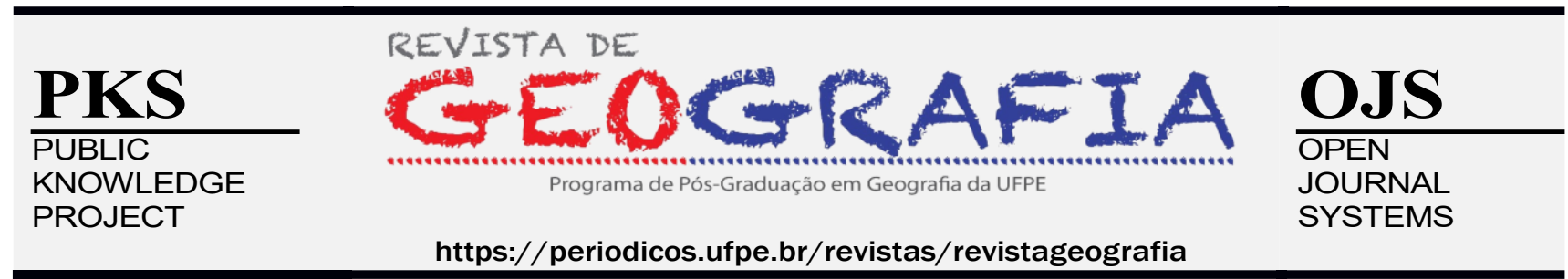

\title{
COOPERATIVISMO E POLÍTICAS PÚBLICAS: A COOPERATIVA AGRÍCOLA DOS PRODUTORES DE VINHO DE JUNDIAÍ (AVA) NO ÂMBITO DO PROJETO MICROBACIAS II
}

\author{
Tamires Regina Rocha ${ }^{1}$, Alan da Silva Vinhaes ${ }^{2}$
}

\begin{abstract}
Universidade Estadual Paulista "Júlio de Mesquita Filho" Campus de Presidente Prudente. Email: tamiresrerocha@hotmail.com. Orcid: https://orcid.org/0000-0002-5358-1174

2 Universidade Estadual Paulista "Júlio de Mesquita Filho" Campus de Presidente Prudente. Email: asvinhaes2013@gmail.com.Orcid: https://orcid.org/0000-0002-3072-2050
\end{abstract}

Artigo recebido em 07/07/2021 e aceito em 18/09/2021

\section{RESUMO}

O artigo tem como objetivo principal analisar a Cooperativa Agrícola dos Produtores de Vinho de Jundiaí (AVA) que foi contemplada no ano de 2013 pelo Projeto Microbacias II. Para alcançar esse objetivo foram realizados os seguintes procedimentos metodológicos: levantamento bibliográfico; aplicação de roteiro de entrevista com o presidente da Cooperativa Agrícola de Vinho de Jundiaí (AVA) e com produtores rurais cooperados. Em relação aos principais resultados alcançados destaca-se a aquisição de máquinas e equipamentos pela Cooperativa AVA para a produção de vinhos, o que resultou na melhoria da qualidade do produto, aumento da produção e assim, proporcionou maior rentabilidade para os produtores rurais cooperados.

Palavras-chave: Microbacias II; Estado; Políticas Públicas.

\section{COOPERATIVISM AND PUBLIC POLICIES: THE AGRICULTURAL COOPERATIVE OF THE JUNDIAÍ WINE PRODUCERS (AVA) IN THE FRAMEWORK OF THE MICROBACIAS II PROJECT}

\begin{abstract}
The article's main objective is to analyze the Jundiaí Wine Producers' Agricultural Cooperative (AVA) that was contemplated in 2013 by the Microbacias II Project. To achieve this objective, the following methodological procedures were carried out: bibliographic survey; application of an interview script with the president of the Jundiaí Agricultural Cooperative (AVA) and with cooperative rural producers. In relation to the main results achieved, the acquisition of machinery and equipment by Cooperativa AVA stands out for the production of wines, which resulted in the improvement of product quality, increased production and thus, provided greater profitability for cooperative rural producers.
\end{abstract}

Keywords: Microbasins II, State, Public Policies. 


\section{COOPERATIVISMO Y POLÍTICAS PÚBLICAS: LA COOPERATIVA AGRÍCOLA DE LOS PRODUCTORES DE VINO DE JUNDIAÍ (AVA) EN EL MARCO DEL PROYECTO MICROBACIAS II}

\section{RESUMEN}

El objetivo principal del artículo es analizar la Cooperativa Agrícola de Productores de Vino de Jundiaí (AVA) que fue contemplada en 2013 por el Proyecto Microbacias II. Para lograr este objetivo, se llevaron a cabo los siguientes procedimientos metodológicos: encuesta bibliográfica; Solicitud de un guión de entrevista con el presidente de la Cooperativa Agrícola Jundiaí (AVA) y con cooperativas de productores rurales. En relación con los principales resultados alcanzados, lo más destacado es la adquisición de maquinaria y equipo por parte de la Cooperativa AVA para la producción de vinos, lo que resultó en la mejora de la calidad del producto, aumento de la producción y, por lo tanto, mayor rentabilidad para los productores rurales cooperativos.

Palabras clave: Microbacias II, Estado, Políticas públicas.

\section{INTRODUÇÃO}

Quando se analisa a presença de cooperativas, associações e grupos de interesse de agricultores familiares é necessário compreender como essas organizações coletivas, formais e informais, que tem diferentes finalidades, se tornaram fundamentais para proporcionar o acesso às máquinas e equipamentos que facilitam o trabalho diário realizado em pequenas propriedades rurais, especialmente em virtude da falta de mão-de-obra.

O artigo tem como objetivo analisar a Cooperativa Agrícola dos Produtores de Vinho de Jundiaí (AVA) que participou do Projeto de Microbacias II por meio da aprovação do seu plano de negócios.

No período de 2011 e 2018, a Coordenadoria de Assistência Técnica Integral (CATI) executou o Projeto de Desenvolvimento Rural Sustentável - Microbacias II - Acesso ao Mercado, “cujo objetivo principal foi promover o desenvolvimento rural sustentável, a inclusão social, contribuir para a preservação dos recursos naturais, ampliar a renda e o bem-estar dos beneficiários bem como aquisição de máquinas e equipamentos para produção" (VINHAES et al., 2018, p. 1323).

Para a elaboração do artigo, foram realizadas as seguintes etapas: seleção e leitura de material bibliográfico (livros, artigos científicos, dissertações, teses, etc.) que tratam dos temas relacionados às políticas públicas; desenvolvimento rural; breve contextualização do município de Jundiaí, no qual está situada a Cooperativa (AVA); a importância da agricultura familiar no país; ao cooperativismo e associativismo e do Projeto de Microbacias II.

Também foi realizada pesquisa empírica com a elaboração de roteiro que foi utilizado na entrevista com o presidente da cooperativa (AVA) para a coleta de dados e informações sobre o processo de formação, principais objetivos, importância e papel desempenhado pela cooperativa; e 
de formulário destinado a aplicação junto a seis (6) produtores rurais localizados nos Bairros Rurais do Poste e do Caxambú no município de Jundiaí que participam da cooperativa.

O texto se encontra estruturado em três seções, além da introdução, das considerações finais e das referências. Na primeira seção, se aborda o processo de modernização da agricultura, a descentralização e as políticas públicas da década de 1990 voltadas para o meio rural; na segunda são apresentadas as características e os objetivos da primeira fase do Programa Estadual de Microbacias Hidrográficas (PEMH) que possuía um caráter ambiental e da segunda edição, denominada de Projeto de Desenvolvimento Rural Sustentável Microbacias II - Acesso ao Mercado que tem como objetivo promover a inserção dos pequenos produtores rurais ao mercado e que a Cooperativa Agrícola dos Produtores de Vinho de Jundiaí (AVA) foi beneficiada com recursos; e, por fim, na última seção histórico do município de Jundiaí, a importância da agricultura familiar no país, os conceitos de associativismo e cooperativismo e é apresentada a cooperativa (AVA), o seu papel desempenhado e a importância na reprodução social dos agricultores, garantindo sua participação numa política pública de âmbito estadual.

\section{O PROCESSO DE MODERNIZAÇÃO DA AGRICULTURA, A DESCENTRALIZAÇÃO E AS POLÍTICAS PÚBLICAS DOS ANOS DE 1990}

Priori et al. (2012) destacam que o processo de modernização agrícola se efetivou na década de 1960, período em que a produção agrícola brasileira se incorporou nos aspectos técnicos ao setor urbano e industrial, com o objetivo de alcançar maiores ganhos econômicos.

Na década de 1960,

[...] era evidente o desafio da sociedade brasileira diante da urgência em reestruturar alguns mecanismos administrativos, políticos, fiscais e agrários. A eminente concentração da propriedade fundiária, as condições de trabalho precárias no campo, principalmente em relação ao baixo índice de assalariamento, associadas a uma base técnica que deixava a desejar, renderam muitos debates em relação à necessidade de uma Reforma Agrária no Brasil (PRIORI et al., 2012, p. 118).

No início da ditadura militar (1964) discutia-se de que maneira o país conseguiria aumentar sua produtividade agrícola. "Duas visões distintas predominavam: a que defendia o aumento da produtividade por meio da reforma agrária, e a que defendia ser necessária a adoção dos pacotes tecnológicos pelos agricultores, sem tocar na questão fundiária” (ZAMBERLAM; FRONCHET, 2001 apud ANDRADES; GANIMI, 2007, p. 21).

Com a intensificação do processo de modernização da agricultura brasileira a partir dos anos de 1960 , 
[...] as políticas públicas para o meio rural privilegiaram os setores mais capitalizados e a esfera produtiva das commodities voltadas ao mercado internacional e produzidas em larga escala; o resultado dessas políticas públicas foi altamente negativo, uma vez que grande parte dos agricultores ficaram à margem dos benefícios oferecidos pela política agrícola, sobretudo nos itens relativos ao crédito rural, aos preços mínimos e ao seguro da produção (MATTEI, 2014, p. 71).

Priori et al. (2012, p. 120) expõem que

[...] esse projeto de modernização não ocorreu de forma homogênea em todo o Brasil. Houve uma concentração dos investimentos nas regiões Sul, Sudeste e parte do Centro-oeste. Além do mais, a opção pela estruturação de uma economia urbanoindustrial pelo governo brasileiro privilegiou a transferência de recursos do campo para o financiamento do desenvolvimento do projeto nacional.

Lazzari e Souza (2017, p. 5) relatam que a modernização do campo fez com que pequenos produtores rurais "fossem expropriados, dando lugar aos moldes empresariais de organização da produção, garantindo que a divisão desigual de terras continuasse a ser efetiva, aumentando ainda mais as diferenças".

Como aponta Teixeira (2005, p. 24), “a década de 1960 marcou o início de um novo modelo econômico brasileiro, substituindo o chamado modelo de substituição de importações pela modernização do setor agrário e formação do Complexo Agroindustrial”.

A modernização da agricultura se caracterizou pela mecanização e intenso uso de insumos químicos e defensivos agrícolas, causando erosão e contaminação do solo, diminuindo assim a cobertura vegetal e degradando os recursos hídricos (CATI, 2001).

Hespanhol (2008, p. 129) destaca que entre as décadas de 1950 e 1980, “as políticas públicas tiveram um caráter marcadamente setorial, caracterizadas quase que exclusivamente pelo seu viés agrícola, privilegiando, sobretudo os grandes produtores rurais vinculados às demandas do mercado externo".

Na década de 1980 ocorreram significativas mudanças no cenário político, com o fim da ditadura militar e a elaboração de uma nova Constituição Federal no ano de 1988, a qual trouxe consigo um novo marco para a formulação e implementação de políticas públicas, pois conferiu autonomia política e administrativa aos municípios. Estes passaram a ser reconhecidos oficialmente como entes federativos e a ter recursos financeiros e autonomia para formular e implementar políticas públicas. Esta situação trouxe o desafio da coordenação intergovernamental na elaboração e execução de políticas públicas.

Até o ano de 1988, os municípios brasileiros executavam poucas políticas porque não dispunham dos recursos necessários. Com a descentralização fiscal e administrativa, propiciada pela 
Carta Magna, havia a perspectiva de que os municípios passariam a criar novas políticas derivadas da descentralização fiscal.

Com todo o processo de redemocratização do país e a promulgação da Constituição de 1988,

[...] ocorreu um reordenamento do Estado brasileiro, levando a uma descentralização das ações governamentais com o intuito de ampliar o acesso aos recursos públicos, por um lado, e de democratizar as próprias políticas, por outro. Esse movimento de democratização possibilitou uma maior intervenção dos atores sociais, a qual viabilizou através dos conselhos gestores de políticas gerais de desenvolvimento nas diversas esferas governamentais (MATTEI, 2014, p. 74).

Hespanhol (2013) destaca que, na década de 1990 e no início do século XXI, houve importantes mudanças nas políticas destinadas ao meio rural, principalmente em relação à agricultura familiar. Diversos programas foram criados para atender aos agricultores familiares, com destaque para o Programa Nacional de Fortalecimento da Agricultura Familiar (PRONAF).

Assim, a criação do PRONAF representou:

[...] a legitimação, por parte do Estado brasileiro, de uma nova categoria social - os agricultores familiares - que até então era praticamente marginalizada em termos de acesso aos benefícios da política agrícola, bem como designada por termos como pequenos produtores, produtores familiares, produtores de baixa renda ou agricultores de subsistências (MATTEI, 2014, p.72).

Para Neves Neto (2014), além da linha individual do PRONAF (crédito de custeio e investimento), foi lançado um crédito coletivo, denominado PRONAF-Infraestrutura e Serviços Municipais:

[...] por meio do qual eram destinados recursos financeiros para a melhoria da infraestrutura produtiva dos municípios com forte presença de agricultores familiares. Para o acesso a esse crédito, os municípios deveriam ter um Conselho Municipal de Desenvolvimento Rural constituído e dispor de um Plano Municipal de Desenvolvimento Rural (NEVES NETO, 2014, p. 85).

Hespanhol (2008) ainda acrescenta que o PRONAF foi importante tanto economicamente, tendo em vista que parte dos produtores rurais conseguiram acesso ao financiamento rural subsidiado, quanto socialmente, pois foi reconhecida, pelo menos em termos do discurso oficial, a importância da agricultura familiar na produção de alimentos, na diversidade cultural e no cuidado com o meio ambiente.

Portanto, o debate sobre "o papel da agricultura familiar no desenvolvimento brasileiro foi ganhando força ao longo do tempo, impulsionado, principalmente, pela concepção de desenvolvimento duradouro, geração de emprego e renda, segurança alimentar e desenvolvimento local" (BEZERRA; SCHLINDWEIN, 2017, p. 4). 
De acordo com a Lei Federal n. 11.326, de 24 de julho de 2006, no artigo $3^{\circ}$ são destacadas como características primordiais para se enquadrarem como agricultores familiares:

(I) não possuir área maior do que quatro módulos fiscais; (II) a mão de obra utilizada nas atividades econômicas ser predominantemente familiar e (III) o maior percentual da renda ser obtido das atividades econômicas do estabelecimento. Como agricultura familiar tradicional entendem-se, neste estudo, os agricultores enquadrados na Lei Federal 11.326, de 24 de julho de 2006, não pertencentes à reforma agrária (BEZERRA; SCHLINDWEIN, 2017, p. 3).

Sacco dos Anjos e Becker (2014, p. 94) expõem que as duas últimas décadas caracterizou um período de consolidação da agricultura familiar no Brasil. Até então predominava uma intrínseca associação entre a forma social de produção e a fragilidade estrutural. O destaque, no decorrer dos anos, incidiu sobre a instituição de políticas compensatórias que até então "se denominava "pequena produção", mas também aos trabalhadores rurais, meeiros, lavradores e outros atores sociais, que foram marcados pelo estigma da pobreza e pela irrelevância em termos da intervenção dos poderes públicos".

Contudo, a implantação de políticas públicas para o desenvolvimento rural sustentável requer, entre outras coisas, uma:

[...] mudança de foco nas estratégias de desenvolvimento rural, historicamente utilizadas no Brasil, onde, conforme afirma Ehlers (1996), a exemplo de outros países em desenvolvimento, as propriedades patronais foram consideradas mais adequadas para a implantação do padrão convencional, tendo a agricultura familiar sido relegada a segundo plano, principalmente no que se refere a incentivos e acesso a crédito (HESPANHOL, 2008, p. 382).

Na próxima seção será analisado o Programa Estadual de Microbacias Hidrográficas (PEMH) e o Projeto de Desenvolvimento Rural Sustentável Microbacias II - Acesso ao Mercado, "uma política pública que têm como objetivo ampliar a competitividade e proporcionar o acesso ao mercado aos agricultores familiares organizados em associações e cooperativas no Estado de São Paulo" (CATI, 20--).

\section{O PROGRAMA ESTADUAL DE MICROBACIAS HIDROGRÁFICAS (PEMH) I E O PROJETO DE DESENVOLVIMENTO RURAL SUSTENTÁVEL MICROBACIAS II- ACESSO AO MERCADO}

Para analisarmos o Projeto de Desenvolvimento Rural Sustentável Microbacias II - Acesso ao Mercado do Estado de São Paulo é necessário realizar uma breve caracterização da primeira edição dessa política pública, a qual era denominada de Programa Estadual de Microbacias Hidrográficas (PEMH), para que se tenha clareza sobre as diferenças entre as duas edições do programa. 
O Programa Estadual de Microbacias Hidrográficas I (PEMH) em sua primeira edição (2000-2008) contou com o apoio do Banco Mundial e possuía, em termos oficiais, três princípios básicos: "a busca por uma sustentabilidade socioeconômica e ambiental na microbacia (unidade física de intervenção do programa), participação e envolvimento da sociedade civil, descentralização e transparência nas ações governamentais" (FONTES, 2006 apud NEVES NETO, 2009, p. 4).

Neves Neto (2009) expõe que o "Programa de Microbacias teve um total estimado em US\$ 124,740,200.00. Desse total, US\$ 55,348,200.00 foram financiados pelo Banco Mundial e o restante, US\$ 69,392,000.00 foi como contrapartida do Estado de São Paulo".

De acordo com Clemente e Oliveira (2015, p. 22) “o PEMH teve como objetivo principal expandir o desenvolvimento rural sustentável atuando em ações de cunho agronômico, ambiental e socioeconômico".

Assim, o Programa de Microbacias Hidrográficas I teve como meta: "garantir a segurança alimentar; viabilizar economicamente as unidades de produção agropecuária; fortalecer as formas de organização social no campo; preservar o meio ambiente e melhorar a qualidade de vida das famílias rurais" (CLEMENTE E OLIVEIRA, 2015, p. 24).

Portanto, o PEMH direcionou suas respectivas ações nos pequenos proprietários rurais, atribuindo a maior demanda de recursos financeiros para este grupo. Entre as práticas individuais oferecidas destacam-se:

adubação verde, cerca de proteção de APP, faixa de retenção, terraceamento, calcário, fossas sépticas e piqueteamento. As práticas coletivas foram: construção de abastecedouros, aquisição de distribuidor de calcário, roçadeira e escarificador/subsolador, chegaram a ter até $90 \%$ dos seus custos subvencionados pelo programa para esta categoria de proprietários (CLEMENTE E OLIVEIRA, 2015, p. 25).

De acordo com a Coordenadoria de Assistência Técnica Integral (CATI, 2001), o PEMH teve como finalidade proporcionar o desenvolvimento rural no Estado de São Paulo, resultando em melhoria dos níveis de renda, maior produtividade, redução de custos e reorientação técnica agronômica. Para Hespanhol (2008) apud Clemente e Oliveira (2015, p. 26):

Nas propriedades rurais, o Programa de Microbacias Hidrográficas implementou ações que se pautaram na construção de cercas para proteção das áreas de preservação permanente (APPs), sobretudo em torno dos cursos deágua, represas e nascentes, fornecimento de mudas para o plantio nas APPs, disponibilização de hora/máquina para a realização de obras de terraceamento e construção de terraços e curvas de nível, construção de poços para o abastecimento de água a grupos de proprietários das microbacias, oferta de recursos financeiros para a aquisição de 
implementos agrícolas, calcário e fertilizantes e, também, estímulo à formação de associações de produtores rurais nas respectivas microbacias.

Para conseguir os benefícios do programa, os municípios atendidos teriam que atender a dois requisitos básicos, conforme também destaca Neves Neto (2014, p. 152):

[...] possuir um Conselho Municipal de Desenvolvimento Rural (CMDR), com participação de diferentes setores da sociedade civil e formalizar convênio com a Secretaria de Agricultura e Abastecimento, apresentando as diferentes operações do programa, contendo um plano de trabalho com todas as ações previstas no município.

Neves Neto (2013, p. 187) destaca que havia a necessidade de "os produtores rurais formarem grupos, de pelo menos cinco produtores, para elaborar um Projeto de Empreendimento Comunitário - PEC. Para o acesso ao incentivo, foi necessário que cada estabelecimento rural participante elaborasse os Planos Individuais de Propriedade - PIP”.

Clemente e Oliveira (2015) expõem que, durante a primeira edição do Programa de Microbacias ocorreu um crescimento no número de associações de produtores rurais, isto só ocorreu devido à motivação dos produtores rurais para acessar os recursos financeiros do programa. Todavia, após a finalização desta primeira edição, muitas associações de produtores rurais não conseguiram se manter e acabaram desativadas.

Para Hespanhol (2008, p. 10), o Programa de Microbacias teve pontos positivos e negativos, pois "o maior ou menor êxito dependeu basicamente do interesse e do empenho das autoridades municipais, da atuação dos técnicos executores e do envolvimento e nível de organização dos produtores rurais".

Ao final da primeira edição do Programa de Microbacias no Estado de São Paulo, concluise que

[...] as suas ações se concentraram nos aspectos agronômico-conservacionistas, tais como o controle de processos erosivos, cercamento de Áreas de Preservação Permanente (APP), adubação verde e readequação de estradas rurais. Neves Neto (2014) considera que mesmo com estas ações o programa foi insuficiente para promover o desenvolvimento rural sustentável, pois há necessidade de ações governamentais concretas para garantir renda e emprego à população que vive nos espaços rurais (VINHAES et al., 2018, p. 1323).

No ano de 2011, houve o lançamento da segunda edição do Programa de Microbacias que tinha como principal objetivo: propiciar a inserção dos pequenos produtores rurais ao mercado, com aspectos diferentes do PEMH que possuía caráter ambiental.

O Projeto de Desenvolvimento Rural Sustentável Microbacias II - Acesso ao Mercado é uma ação do Governo do Estado de São Paulo, com financiamento parcial do Banco Mundial, executado 
pela Secretaria da Agricultura e Abastecimento, através da Coordenadoria de Assistência Técnica Integral (CATI) que é responsável por $81,2 \%$ do total dos recursos disponíveis e pela Secretaria do Meio Ambiente, por intermédio da Coordenadoria de Biodiversidade e Recursos Naturais (CBRN) responsável por $18,8 \%$ dos recursos. Com valor total de US\$ 130 milhões, começou a ser executado no ano de 2011, e foi previsto inicialmente sua de conclusão no ano de 2015. No entanto, o projeto foi prorrogado até o mês de setembro de 2018, quando foi concluído (CATI, 20--).

No Quadro 1 são apresentadas, sinteticamente, as principais diferenças entre as duas edições do programa.

Quadro 1. Comparação entre as duas edições do Programa de Microbacias no Estado de São Paulo

\begin{tabular}{|c|c|c|}
\hline & PEMH & MICROBACIAS II \\
\hline Foco & Ambiental & $\begin{array}{c}* \text { Aumento da competitividade } \\
* \text { Aumento de emprego e renda }\end{array}$ \\
\hline $\begin{array}{c}\text { Unidade de } \\
\text { Trabalho }\end{array}$ & Microbacia Hidrográfica & $\begin{array}{c}\text { Organização de produtores } \\
\text { (Associação ou Cooperativa) }\end{array}$ \\
\hline Beneficiários & Produtores Individuais e/ou Coletivos & $\begin{array}{c}\text { Agricultores estruturados em } \\
\text { numa cadeia produtiva e } \\
\text { organizados em associação ou } \\
\text { cooperativa }\end{array}$ \\
\hline Execução & Associações - fortalecimento & Plano de Negócio \\
\hline
\end{tabular}

Fonte: Neves Neto (2014, p. 100).

Para ter o apoio financeiro do projeto,

[...] a associação ou cooperativa necessita apresentar um plano de negócio. Este plano deve conter um número mínimo de 15 participantes e $50 \%$ devem ser classificados como agricultores familiares. Às comunidades tradicionais, sendo indígena ou quilombola, somente receberá os recursos para a implantação dos seus projetos se possuírem a titulação da propriedade reconhecida através de órgãos oficiais e podem apresentar seu projeto a qualquer momento, não dependendo de abertura de chamadas. Portanto, o percentual de apoio em relação ao projeto e do plano de negócio depende do número de agricultores familiares, conforme especificado no Quadro 2 (CATI, 20--). 
Quadro 2. Benefícios e Valores máximos apoiados na iniciativa de Negócio do Projeto Microbacias II

\begin{tabular}{|c|c|c|l|}
\hline Beneficiários & $\begin{array}{c}\text { Valor Máximo } \\
\text { Apoiado RS }\end{array}$ & \% de Apoio & $\begin{array}{l}\text { Caracterização dos Proponentes da } \\
\text { Proposta de Iniciativa de Negócio }\end{array}$ \\
\hline $\begin{array}{c}\text { Associações ou Cooperativas de } \\
\text { Produtores Rurais }\end{array}$ & $800.000,00$ & Até $70 \%$ & $\begin{array}{l}\text { Proposta de iniciativa de negócio } \\
\text { constituída por grupo com mais de } 70 \% \\
\text { de agricultores familiares }(>70 \%)\end{array}$ \\
\cline { 2 - 4 } & Até 50\% & $\begin{array}{l}\text { Proposta de iniciativa de negócio } \\
\text { constituída por grupo com mais de } 50 \% \\
\text { e até } 70 \% \text { de agricultores familiares }(> \\
50 \text { a } 70 \%) .\end{array}$ \\
\hline $\begin{array}{c}\text { Associações ou Cooperativas de } \\
\text { Comunidades Tradicionais } \\
\text { (Indígenas e Quilombolas) }\end{array}$ & $200.000,00$ & $99 \%$ & $\begin{array}{l}\text { Projetos Comunitários de Comunidades } \\
\text { Tradicionais (Indígenas e } \\
\text { Quilombolas) }\end{array}$ \\
\hline
\end{tabular}

Fonte: São Paulo (2015, p. 24).

"O apoio financeiro individual é restrito aos agricultores familiares. Nesse caso o reembolso será de até $70 \%$ do valor do bem ou serviço, limitado a um teto de $\mathrm{R} \$ 10.000,00$ por agricultor durante todo o projeto" (VINHAES, et al., 2018, p. 1328).

As metas do projeto Microbacias II foram:

[...] o atendimento para 22.000 famílias de agricultores familiares e 350 famílias de tribos indígenas e 300 comunidades quilombolas; 30 mil famílias introduzidas nas organizações de produtores rurais receberão assistência técnica e capacitação do programa; 1.200 associações/cooperativas de produtores serão identificadas e estimuladas a apresentarem propostas de negócios; abranger 550 municípios do Estado de São Paulo, que já possui estabelecido o convênio com a SAA/CATI e possuam os Planos Municipais de Desenvolvimento Rural Sustentável elaborados, acompanhados e monitorados; capacitar 550 Conselhos Municipais de Desenvolvimento Rural para elaboração e acompanhamento da execução dos Planos Municipais de Desenvolvimento Rural Sustentável; - readequar $18.000 \mathrm{~km}$ de estradas rurais em 120 municípios, para permitir a trafegabilidade o ano inteiro; apoiar 40 subprojetos ambientais; e - inserir dois programas de serviços ambientais (SÃO PAULO, 2010b, p. 5).

Entretanto, o produtor rural pode ter acesso a benefícios individuais do programa, caso esteja relacionado à proposta de iniciativa de negócio aprovada. Cabe destacar que o produtor rural pode ser reembolsado parcialmente dos investimentos realizados em relação a infraestrutura da propriedade associada ao negócio proposto.

Poderão ser feitos investimentos em:

1) sistemas de irrigação, máquinas e equipamentos agropecuários, entre outros; 2) na adequação da propriedade às responsabilidades sociais e ambientais, quando forem importantes para o fortalecimento do negócio proposto pela organização e aqueles necessários para adequação da propriedade à responsabilidade social e ambiental, exigidos em processos de certificação; 3) na realização de mudanças orientadas para a melhoria tecnológica do negócio proposto; 4) na implantação de práticas agrícolas sustentáveis, quando forem importantes para o fortalecimento do negócio proposto pela organização; e 5) na recuperação de áreas degradadas e conservação dos recursos naturais (controle de erosão, recuperação de APP), quando 
forem importantes para o fortalecimento do negócio proposto pela organização (SÃO PAULO, 2015).

Nos municípios em que houve uma proposta de negócio aprovada pelo Microbacias II, a prefeitura municipal poderia demandar obras de restauração de estradas rurais, através de convênio firmado com a Secretaria de Agricultura e Abastecimento do Estado de São Paulo (NEVES NETO, 2013).

Porém, a exemplo de outras políticas públicas, Neves Neto (2014, p. 98) ressalta que o projeto Microbacias II - Acesso ao Mercado

[...] é altamente seletivo e excludente, por priorizar um pequeno número de produtores (inseridos num plano de negócio) e se restringir a organizações rurais com maior nível de capitalização, as quais normalmente apresentam condições mais favoráveis para enfrentar as vicissitudes do mercado, independente do apoio oficial. Novamente, os produtores rurais descapitalizados, que enfrentam graves problemas ambientais em suas propriedades ficarão à margem dessa política pública, financiada com recursos de toda a sociedade.

O projeto finalizado contou com 138 planos de negócios aprovados na sexta chamada (Tabela 1), ou seja, o dobro da quinta chamada. Houve também o aumento no valor das propostas e no valor apoiado pelo projeto em comparação com as chamadas anteriores. Esse aumento no número de planos de negócios aprovados e nos valores apoiado pelo projeto ocorreu devido ao maior interesse das associações e/ou cooperativas em buscarem novos meios para se fortalecerem no mercado regional.

Tabela 1. Chamadas Públicas do Projeto de Desenvolvimento Rural Sustentável - Microbacias II - Acesso ao Mercado

\begin{tabular}{c|c|c|c|c|c|c}
\hline Chamada & Interesses & Entregues & Aprovados & Habilitados & $\begin{array}{c}\text { Valor da proposta } \\
\text { em (R\$) }\end{array}$ & $\begin{array}{c}\text { Valor apoiado pelo } \\
\text { Projeto em (R\$) }\end{array}$ \\
\hline 1 & 135 & 92 & 38 & 33 & $19.778 .538,77$ & $13.429 .478,76$ \\
\hline 2 & 103 & 98 & 40 & 31 & $17.492 .029,50$ & $11.904 .432,21$ \\
\hline 3 & 65 & 38 & 35 & 23 & $13.838 .667,26$ & $9.454 .586,94$ \\
\hline 4 & 65 & 60 & 52 & 45 & $29.921 .562,91$ & $18.772 .192,41$ \\
\hline 5 & 90 & 70 & 61 & 55 & $30.057 .653,29$ & $20.761 .907,32$ \\
\hline 6 & - & - & 138 & 136 & $91.430 .259,51$ & $58.474 .753,42$ \\
\hline
\end{tabular}

Fonte: CATI, 2011.

Por fim, o Microbacias II propiciou a forte integração com os municípios ao oferecer um sistema informatizado georreferenciado de gestão da malha viária local, além de apoiar financeiramente a infraestrutura municipal, sobretudo a restauração das estradas rurais não asfaltadas, pois são consideradas essenciais para o acesso a cidade. Em relação à Coordenadoria de Assistência Técnica Integral (CATI), o Microbacias propiciou a melhoria na estrutura física (prédios utilizados 
pelas Casas da Agricultura), a capacitação do quadro de funcionários e a aquisição de equipamentos e veículos.

Portanto, na próxima seção será abordado o papel do Projeto de Microbacias II na Cooperativa Agrícola dos Produtores de Vinho de Jundiaí (AVA).

\section{A IMPORTÂNCIA DA COOPERATIVA AGRÍCOLA DOS PRODUTORES DE VINHO DE JUNDIAÍ (AVA) NA REPRODUÇÃO SOCIAL DOS AGRICULTORES/COOPERADOS COM ÊNFASE AO PROJETO DE MICROBACIAS II}

O município de Jundiaí possui localização privilegiada, estando entre as regiões de Campinas e São Paulo, além de ser cortada por duas vias de acesso consideradas muito importantes, quais sejam a Rodovia Anhanguera e Bandeirantes.

Segundo o IBGE (2019), o município de Jundiaí (Mapa 1) conta com uma população total de 414.810 habitantes. Ainda de acordo com o IBGE - Censo Demográfico de 2010, a população total correspondia a 370.126 habitantes, sendo que a população urbana era de $354.204(95,7 \%)$ e a população rural de 15.922 (4,3\%). A densidade demográfica no município era de 858,42 km² no ano de 2010. Em 2016, segundo o IBGE, o município possuía o $5^{\circ}$ maior PIB industrial do Estado de São Paulo e o $7^{\circ}$ maior PIB em prestação de serviços e comércio. Apesar dessa importância do setor industrial e de comércio e serviços, a agricultura e o espaço rural tiveram e ainda tem importância fundamental no processo de formação e consolidação do município, sendo conhecido nacionalmente como a capital da uva e do morango.

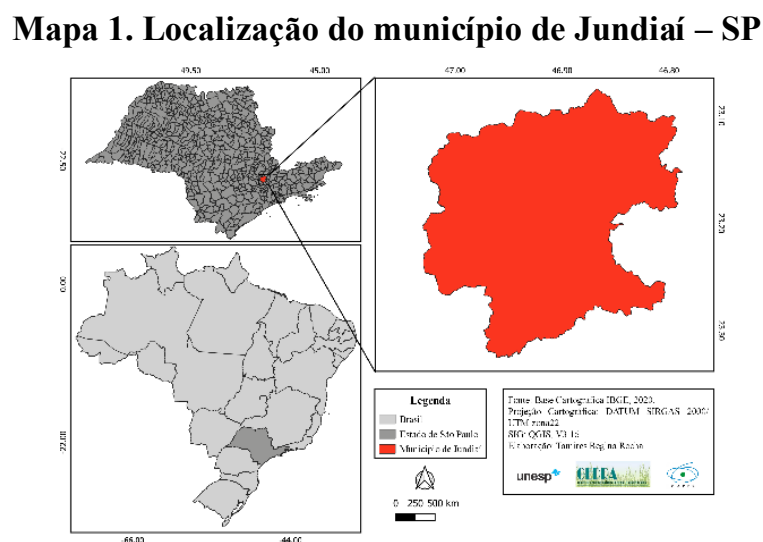

No município de Jundiai há uma participação importante de pequenas propriedades rurais que são responsáveis pela maior parte da produção agropecuária dessa localidade. No entanto, esses pequenos proprietários apresentam inúmeras dificuldades para se reproduzirem socialmente no campo. 
Dessa forma, como afirma Veiga (1996), uma nova estratégia de desenvolvimento rural para o Brasil está embasada na agricultura familiar, na sua expansão e no seu fortalecimento. Para isso, as políticas públicas, o fortalecimento do associativismo e do cooperativismo, bem como o apoio do Estado, são necessários para combater as incertezas e instabilidades que existem no setor, garantindo assim preços reduzidos aos consumidores e qualidade de vida e o bem-estar dos agricultores familiares.

O associativismo, em sua acepção mais restrita, se constitui numa alternativa necessária que pode viabilizar as atividades econômicas, possibilitando aos trabalhadores e pequenos proprietários rurais, um caminho para participar do mercado em melhores condições de concorrência (CARTILHA DO COOPERATIVISMO E ASSOCIATIVISMO, 2015).

De acordo Cardoso (2014) apud Mumic et al. (2015), o associativismo não tem como objetivo principal a atividade econômica, mas sim a defesa dos interesses de um grupo de pessoas que descobriu na união de esforços uma solução mais prospera para determinados problemas.

Em relação as cooperativas, "no âmbito do espaço rural, o surgimento das cooperativas e a participação dos produtores foram estimulados principalmente pela obtenção de crédito agrícola, melhoria nas condições de produção e na comercialização dos produtos” (MELO, 2014, p. 119). Essas características, aliadas às políticas governamentais de incentivo ao cooperativismo, proporcionaram o crescimento da prática cooperativista no Brasil.

De acordo com Canabarro et al. (2005) para que haja o efetivo funcionamento de uma cooperativa são necessários:

a) adesão livre e voluntária - participa quem quiser e pelo tempo que quiser; b) controle democrático pelos sócios - os sócios têm igualdade de votação (um sócio, um voto); c) participação econômica dos sócios - há a contribuição equitativa dos sócios que controlam democraticamente o capital da cooperativa; d) autonomia e independência - cada um deve assumir responsabilidade solidária com o grupo; e) educação, treinamento e formação - as cooperativas devem proporcionar educação e treinamentos para os sócios, visando contribuir efetivamente para o desenvolvimento da cooperativa; f) cooperação entre as cooperativas, visando à integração entre as cooperativas do mesmo ou de outro segmento; g) preocupação com a comunidade buscar o crescimento dentro de uma consciência ecologicamente sustentável, promovendo transformações sociais e atendendo ao bem estar dos cooperados e da comunidade em geral, (CANABARRO et al., 2005, p. 3).

Assim, "é possível compreender que as cooperativas apresentam uma maior gama de oportunidades e formas de sistematizar os lucros a seus participantes, proporcionando uma maior representatividade na economia de mercado" (SILVA, 2016, p. 54). 
Portanto, para que ocorra o processo de formação de cooperativas são necessários alguns princípios básicos, como o sentimento de confiança entre os integrantes, objetivos e metas comuns, senso de coletividade, dentre outros.

\section{A Cooperativa Agrícola dos Produtores de Vinho de Jundiaí (AVA)}

A Cooperativa Agrícola dos Produtores de Vinho de Jundiaí (AVA) tem sua origem como uma associação em 2003, em que um grupo de produtores começou a se organizar coletivamente, fundando a então denominada Associação de Viticultores Artesanais (AVA) de Jundiaí, com um total de 13 associados.

Essa associação tinha como objetivo contribuir para o fomento e a organização das atividades artesanais de produção e comercialização de vinhos e derivados da uva, como o suco de uva, vinagre, geleias e licores, sob a forma de sociedade sem fins lucrativos.

De acordo com o atual presidente da cooperativa:

[...] em meio aos fatos, a Associação já não bastava mais, e então, foi decidido que era necessário ir em frente. Foi aí que surgiu a Cooperativa Agrícola de Vinho. A Cooperativa além de manter a tradição, viria como um novo desafio para os produtores; garantir a qualidade dos produtos, abrir novos mercados, e fortalecer a marca do produto: o vinho artesanal (PRESIDENTE DA COOPERATIVA AVA, ENTREVISTA REALIZADA EM SETEMBRO DE 2018).

"E no dia 6 de agosto de 2007, de acordo com a Lei n' 5.764/71, constituiu-se a Cooperativa Agrícola dos Produtores de Vinho - AVA” (VICENTE, 2013, p. 77) (Figura 1). Com inicialmente 15 cooperados, sendo 13 da antiga associação e mais dois (2) que passaram a participar da atual cooperativa. Vale ressaltar que a associação deixou de existir no município, permanecendo apenas a cooperativa.

Figura 1. Logotipo da Cooperativa AVA.

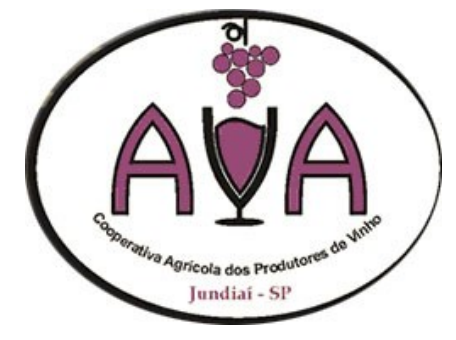

Fonte: Prefeitura de Jundiaí.

De acordo com o presidente entrevistado, a cooperativa tem como objetivo:

[...] manter os produtos dentro das exigências do Ministério da Agricultura, fomentar a divulgação dos produtos e repassar aos cooperados bens de produção e insumos 
necessários ao desenvolvimento de suas atividades (PRESIDENTE DA COOPERATIVA AVA, ENTREVISTA REALIZADA EM SETEMBRO DE 2018).

De acordo com o presidente da cooperativa, no ano de 2018 havia um total de 24 cooperados, sendo 22 do munícipio de Jundiaí, um do município de Jarinu e um do município de São Miguel Arcanjo. O Sr. A.M (presidente da cooperativa) ressaltou que a cooperativa não se empenha em buscar novos cooperados, mas aqueles produtores que buscam legalizar a sua produção de vinho acabam procurando a cooperativa para se inserir nela.

Em relação aos serviços prestados pela cooperativa aos produtores, o presidente ressaltou que os equipamentos fornecidos para todo o processo de produção do vinho, passando pela desengaçadeira (Foto 1) que realiza praticamente sem o contato humano, o esmagamento da uva para a liberação da polpa e do suco da fruta, caracterizando assim o processo de maceração da uva (mistura de sucos, cascas e bagas que colaboram para deixar o vinho mais encorpado e com mais cor) que são automaticamente transportados via mangueira para o tanque de fermentação.

Foto 1. Equipamento para esmagamento da uva - desengaçadeira.

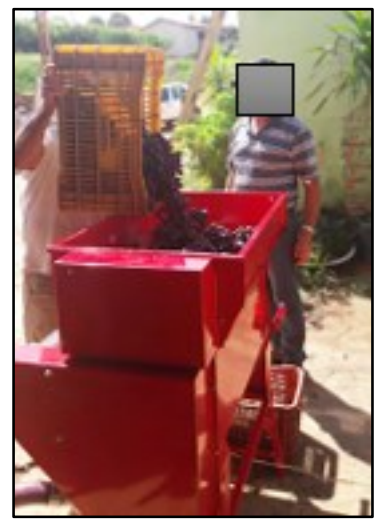

Fonte: Cooperativa AVA, 2018.

O presidente da cooperativa ressaltou que eles adquiriram esse equipamento em virtude da aprovação do plano de negócios do Projeto Microbacias II - Acesso ao Mercado, pois antes eram necessárias três pessoas para o trabalho. Atualmente, com o uso da máquina, é preciso apenas de uma pessoa para o manuseio. Portanto, o uso da máquina propiciou maior produção, porém resultou em várias perdas, como aborda Costa (2010, p. 92), pois a máquina representou "uma ruptura definitiva do produtor direto com o domínio que ainda exercia sobre o processo de produzir; estabeleceu hierarquização e disciplinamento do trabalho; incorporou no processo produtivo uma disciplina autoritária sobre o trabalhador".

Em 2013, a cooperativa, por intermédio da CATI, elaborou um plano de negócios com a participação de 19 cooperados, tendo como objetivo a aquisição de equipamentos para a melhor 
produção do vinho artesanal e que agilizasse o trabalho do vinicultor e, consequentemente, melhorasse a qualidade do produto.

De acordo com o presidente da cooperativa, o plano de negócios foi apresentado/submetido em 2013 e aprovado na $3^{\text {a }}$ chamada do programa, sendo assim, além desse equipamento citado, a cooperativa também adquiriu vários outros que beneficiam, no sistema de rodízio, 19 cooperad os que participam do Microbacias II, tais como: linha de envase itinerante para vinho e champenoise, prensa pneumática, envasadora de seis bicos, capsulador espumante semiautomático, carroceria-baú, entre outros (Foto 2) que contabiliza um valor total de R $\$ 741.577,56$, sendo que R $\$ 519.104,29$ (70\% do valor) foi apoiado pelo Microbacias II, recurso que foi agregado com mais de R\$ 150 mil, em um novo projeto que foi submetido em 2014 e aprovado na $5^{\text {a }}$ chamada do programa para aquisição de outros equipamentos inclusive de uma nova desengaçadeira. Tais equipamentos podem ser instalados e desinstalados em um caminhão com carroceria para o envase móvel de vinho e champanoise.

Foto 2. Equipamentos adquiridos pela Cooperativa AVA pelo projeto de Microbacias II

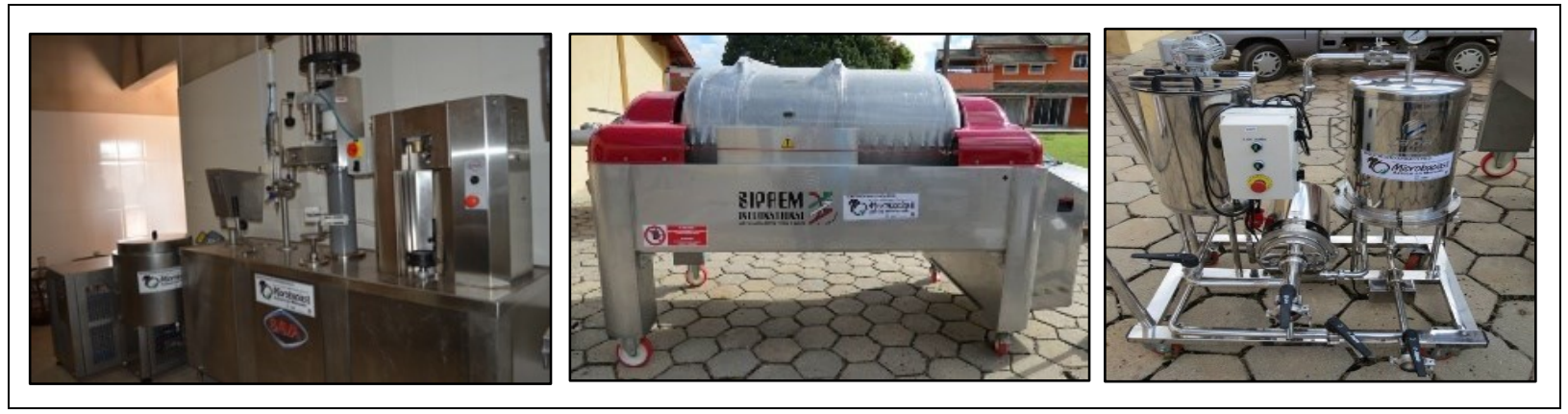

Fonte: Pesquisa de Campo, 2018.

Entretanto, apesar de todos esses equipamentos, de acordo com A.M, presidente da cooperativa, atualmente o principal benefício que a cooperativa oferece para os cooperados é o envase móvel, sendo este o único existente no país (Foto 3).

O envase móvel consiste "justamente em um caminhão com equipamentos capaz de higienizar garrafas, engarrafar o vinho, colocar a rolha e depois colocar o rótulo e tudo isso sem balançar os tonéis em que o líquido fermentou, por pelo menos seis meses, garantindo ainda mais a qualidade do vinho" (PREFEITURA MUNICIPAL DE JUNDIAÍ, 2016). 
Foto 3. Caminhão - envase móvel.

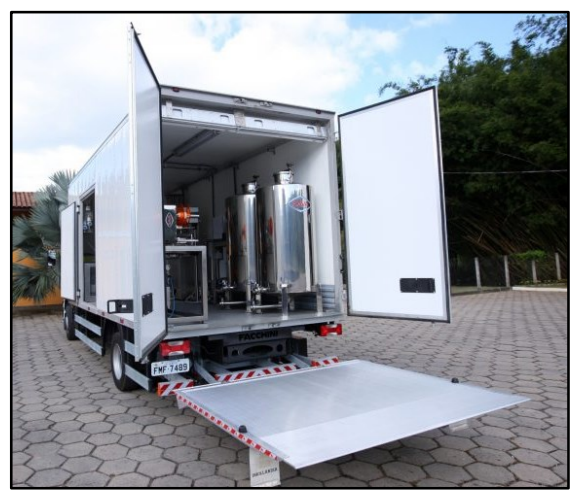

Fonte: Pesquisa de Campo, 2018.

O caminhão de envase móvel financiado por meio do Projeto de Desenvolvimento Rural Sustentável - Microbacias II - Acesso ao Mercado foi orçado em R\$ 750 mil,

[...] porém, R $\$ 522$ mil foram financiados por meio do Projeto de Desenvolvimento Rural Sustentável - Microbacias II - Acesso ao Mercado e os R\$ 228 mil restantes foram pagos pelos cooperados. A capacidade de envase da unidade móvel é de 500 a 800 garrafas por hora. Antes do caminhão, eram necessárias duas pessoas para envasar 50 garrafas por dia (SILVEIRA, 2017, n.p.).

Depois de ser produzido artesanalmente por cada produtor, o vinho vai para tonéis de inox instalados no caminhão. As garrafas são lavadas, checadas e recebem a bebida. $\mathrm{O}$ processo é rápido o suficiente para encher quatro garrafas por minuto (ASSOCIAÇÃO BRASILEIRA DE AÇO INOXIDÁVEL, 2017).

De acordo com o presidente da cooperativa, com a utilização do equipamento, algumas adegas estão conseguindo diversificar a produção. Além do vinho, o espumante está nas prateleiras das adegas sendo comercializado.

Essa organização favorece para melhor mobilidade do produtor, "que não precisa mais transportar a bebida para fora de sua propriedade - um processo que exige cuidado para não haver nenhum tipo de contaminação. Se transferida de um recipiente para outro, como no transporte da vinícola para a cooperativa, a bebida perde qualidade" (DIÁRIO DO COMÉRCIO, 2016).

Para o presidente da cooperativa, tais benefícios concedidos pelo Projeto Microbacias II, estimularam o turismo rural no município de Jundiaí, pois o vinho produzido conforme a legislação, favorece para a sua melhor qualidade, aumenta a velocidade da produção, estimula a diversificação de produtos e, consequentemente, o aumento do número de consumidores.

No tocante à contrapartida financeira exigida pelo Projeto Microbacias II, o Sr. A.M ressaltou que $70 \%$ foram financiados pelo referido programa e os outros $30 \%$ foram rateados entre 
os cooperados. O valor rateado entre os cooperados não foi dividido igualmente entre os participantes do plano de negócios, mas sim, de acordo com a produção de vinho de cada um, ou seja, quem produz mais vinho, pagou mais.

Com relação aos aspectos positivos do projeto de Microbacias II, o presidente ressaltou o fortalecimento do cooperativismo, pois os produtores rurais cooperados que aceitaram participar do plano de negócios, na atualidade, notam os benefícios que a participação em um política pública pode proporcionar, pois mesmo com a burocracia dos projetos, não se arrependem em participar; e, por fim, o próprio subsídio concedido pelo Microbacias (70\% da contrapartida financeira) se torna muito atrativo para a participação nessa política pública.

Quanto aos aspectos negativos do Microbacias II, o entrevistado apontou apenas o término do programa no final de setembro de 2018, enfatizando o anseio de que surja uma outra ação o mais breve possível para promover ainda mais o desenvolvimento da cooperados.

\section{A Cooperativa Agrícola dos Produtores de vinho de Jundiaí (AVA) - uma análise a partir dos agricultores cooperados localizados nos bairros rurais do Poste e do Caxambú}

Os seis (6) agricultores/cooperados entrevistados ressaltaram que a AVA contribuiu para a qualificação técnica da produção do vinho, devido à inclusão de máquinas e equipamentos que possibilitaram a legalização e a divulgação por meio de intercâmbio entre os produtores rurais, com o desenvolvimento de um canal de acesso coletivo de divulgação de seus produtos em feiras e exposições do município e da região.

No Quadro 3 são apresentadas algumas informações sobre os entrevistados, tais como o bairro rural em que estão localizados, a pessoa entrevistada, o nome da família, a idade e o estado civil.

Quadro 3. Identificação dos cooperados da Cooperativa (AVA)

\begin{tabular}{|c|c|c|c|c|}
\hline Nome do Bairro & Entrevistado & Nome da Família & Idade & Estado Civil \\
\hline Bairro Rural do Caxambú & P.M. & Família Maziero & 60 & Casado \\
\hline Bairro Rural do Caxambú & R.S. & Família Sibinel & 60 & Casado \\
\hline Bairro Rural do Caxambú & J.V. & Família Vendramin & 58 & Casado \\
\hline Bairro Rural do Poste & C.M. & Família Marquesin & 66 & Casado \\
\hline Bairro Rural do Poste & J.B. & Família Brunelli & 67 & Casado \\
\hline Bairro Rural do Poste & O.G. & Família Galvão & 97 & Viúvo \\
\hline
\end{tabular}

Fonte: Pesquisa de Campo, 2019.

Em relação ao aumento nas vendas de vinho após fazer parte da cooperativa o entrevistado P.M, cooperado, cuja propriedade rural está situada no Bairro Rural do Caxambú, ressaltou que: 
[...] com certeza, acredito que todos que fazem parte da AVA aumentaram sua comercialização. Obtive um aumento das vendas, não apenas dos vinhos, mas também das cachaças artesanais, champagne, vinagres, espumantes [...] a análise química obrigatória; incluindo certificação para adequação a padrões técnicos definidos nacionalmente melhorou a qualidade do produto. E claro, está certificação passou a ser utilizada como argumento de vendas aos nossos visitantes que procuram produtos de qualidade (ENTREVISTA REALIZADA COM O PRODUTOR RURAL P.M EM MARÇO DE 2019).

Para o produtor rural (O.G) localizado no Bairro Rural do Poste:

[...] os vinhos, as cachaças artesanais, os champagnes e os vinagres, bem como todos os produtos alcoólicos produzidos pelos cooperados, passaram a ter análise química obrigatória; incluindo certificação para adequação a padrões técnicos definidos nacionalmente e melhorando a qualidade de forma geral (ENTREVISTA COM O PRODUTOR RURAL O.G EM MARÇO DE 2019).

Para os produtores rurais entrevistados, os benefícios e os serviços ofertados pela Cooperativa (AVA) estão atendendo suas expectativas, pois a cooperação representa uma maneira para que os pequenos produtores possam inserir-se no mercado, aliando forças e enfrentando as dificuldades perante aos grandes produtores rurais, além de que favorece para a realização de compras conjuntas de suprimentos produtivos; assessoria técnica; proporciona a troca de informações sobre as técnicas de produção entre as adegas nas reuniões promovidas mensalmente e a participação em festas e feiras da região que proporcionam maior visibilidade ao produtor rural e aos produtos comercializados.

Quando perguntados sobre as vantagens de participar da cooperativa, além das que já foram citadas anteriormente, os pesquisados destacaram a importância de impulsionar o Turismo Rural em um polo turístico que Jundiaí está inserido, conhecido como Circuito das Frutas ${ }^{1}$.

Se tratando do Projeto Microbacias II, para os produtores rurais entrevistados, o projeto proporcionou grandes avanços, principalmente no quesito produção, devido à aquisição de equipamentos sofisticados para a produção do vinho artesanal. C.M ressaltou que:

O Microbacias II foi uma das políticas públicas melhores já ofertadas para atender pequenos produtores rurais, se é que não foi a melhor, com "ela" adquirimos máquinas em que apenas uma pessoa pode manusear ao invés de três manualmente [...] foram diversos equipamentos adquiridos: prensa pneumática, envasadora de seis bicos, capsulador espumante semiautomático, carroceria-baú, porém, o envase móvel sem dúvidas foi o que mais nos ajudou, tudo é feito dentro do caminhão, higienização das garrafas, engarrafar o vinho, coloca a rolha e depois coloca o rótulo,

\footnotetext{
${ }^{1}$ Circuito das Frutas é uma região tradicionalmente produtora de frutas de época. São 10 municípios onde se destaca a mão de obra dos europeus que trouxeram para cá seus valores, seus costumes, suas tradições. Os municípios que compõem o Circuito das Frutas são: Atibaia, Indaiatuba, Itatiba, Itupeva, Jarinu, Jundiaí, Louveira, Morungaba, Valinhos e Vinhedo (RIZZATOUR TURISMO, 20--).
} 
quer coisa melhor que isso? (ENTREVISTA REALIZADA EM MARÇO COM PRODUTOR RURAL C.M, 2019).

Além disso foi exposto pelos entrevistados como ponto positivo do projeto, a possibilidade de melhor colocação dos produtos no mercado regional, favorecendo o aumento da renda monetária dos produtores rurais. Destaca-se também o próprio fortalecimento do cooperativismo, pois os produtores rurais que aceitaram participar do plano de negócio, notam a diferença que o proje to propiciou (equipamentos para a produção e envase do vinho, por exemplo) mesmo com a burocracia, e não se arrependem em participar.

De aspecto negativo em relação ao projeto foi destacado pelos produtores rurais a importância de haver uma maior preparação das organizações coletivas para aderirem ao projeto de Microbacias II, pois não havia uma maturidade das organizações, resultando muitas vezes na desistência do plano de negócio.

Entretanto, quando perguntados sobre as perspectivas futuras devido ao fim do Microbacias II, os entrevistados ressaltaram a importância da criação de uma nova política pública voltada para o fortalecimento do pequeno produtor rural, ou mesmo uma reestruturação desta política, favorecendo para o surgimento do Microbacias III que contribua para ampliar a competitividade e proporcionar o acesso ao mercado aos agricultores familiares organizados em associações e cooperativas.

Por fim, de acordo com os produtores rurais entrevistados, espera-se que a cooperativa consiga se impor frente às adversidades existências atualmente em nosso país, principalmente relacionadas a escassez de políticas públicas que atendam aos pequenos produtores rurais.

\section{CONSIDERAÇÕES FINAIS}

A dinâmica instalada na agricultura brasileira a partir da década 1960, ou seja, o processo de modernização, com a chamada Revolução Verde, contribuiu para novas formas de exploração agrícola, resultando em transformações tanto na pecuária, quanto na agricultura.

Porém, o avanço dos meios técnicos-produtivos não atingiu todas as esferas de produtores e propriedades, sendo excludente aos menos favorecidos. Foram beneficiados os grandes proprietários de terra, com a produção voltada para a exportação.

Este estudo evidenciou a importância de uma política pública para o espaço rural, o Microbacias II trouxe uma nova perspectiva aos pequenos produtores rurais participantes dos projetos, pois, historicamente, os maiores beneficiados sempre foram os médios e grandes produtores rurais. 
Entretanto, vale ressaltar que o Microbacias II não atendeu a todos os pequenos produtores rurais do Estado de São Paulo, mas sim, privilegiou os agricultores organizados em associações ou cooperativas; ou aqueles mais capitalizados.

Ficou evidente a contribuição do Projeto Microbacias II sobre a atuação da cooperativa, pois esta passou a proporcionar maior rentabilidade para os produtores rurais e melhoria na qualidade da produção de vinho com maior volume de produção.

Na Cooperativa AVA, após a implementação do Projeto Microbacias II, se viabilizou a compra de máquinas e equipamentos para a produção do vinho artesanal, favoreceu a compra de um caminhão de envase móvel, único em atividade no Brasil, além da intensificação do próprio turismo rural no município de Jundiaí, pois o vinho produzido conforme a legislação em vigor e com equipamentos sofisticados, favoreceu para a sua melhor qualidade, aumentou a velocidade da produção, possibilitou a diversificação de produtos derivados de uva e, consequentemente, o aumento do número de consumidores.

Com a execução da pesquisa concluímos que as organizações coletivas, proporcionam algumas melhorias para os agricultores familiares que fazem parte dela, visto que possibilitam aumentar seu mercado consumidor, aquisições de insumos e acessos às políticas públicas.

Por fim, a pesquisa evidenciou a importância das políticas públicas e das organizações coletivas para o espaço rural, porém, é necessário o aprimoramento de tais políticas, tanto por parte dos gestores, analisando e corrigindo as falhas, quanto dos produtores envolvidos.

\section{AGRADECIMENTOS}

Agradecemos a Coordenação de Aperfeiçoamento de Pessoal de Nível Superior (CAPES) e a Fundação de Amparo a Pesquisa do Estado de São Paulo (FAPESP) nº do processo: 2018/25731-1.

\section{REFERÊNCIAS}

ANDRADES, T. O. de; GANIMI, R. N. Revolução verde e a apropriação capitalista. CES Revista (CES/JF. Impresso), v. 21, p. 43-56, 2007.

ASSOCIAÇÃO BRASILEIRA DO AÇO INOXIDÁVEL. Disponível em < https://www.abinox.org.br/site/agenda-inox-noticiasdetalhes.php? cod $=5796 \& \mathrm{q}=$ Vin $\% 25 \mathrm{C} 3 \% 25 \mathrm{ADcolas}+$ de + Jundia $\% 25 \mathrm{C} 3 \% 25 \mathrm{AD}+$ investem + no + pri meiro+envasador $+\mathrm{m} \% 25 \mathrm{C} 3 \% 25 \mathrm{~B} 3 \mathrm{vel}+\mathrm{do}+$ Brasil $>$ Acesso em 19/09/2018.

BEZERRA, G. J.; SCHLINDWEIN, M. M. Agricultura familiar como geração de renda e desenvolvimento local: uma análise para Dourados, MS, Brasil. Rev. Interações, Campo Grande, MS, v. 18, n. 1, p. 3-15, jan./mar. 2017. 
CANABARRO, L. F. et al. Cooperativa mista dos produtores do Sudeste Goiano: Comigo um perfil de ação empreendedora. Março, 2005.

CARTILHA DO COOPERATIVISMO E ASSOCIATIVISMO. Disponível em <

http://www2.ufersa.edu.br/portal/view/uploads/setores/241/Cartilha\%20de $\% 20$ Associativismo $\% 20 \mathrm{e}$ \%20Cooperativismo > Acesso em: 24/08/2018.

COORDENADORIA DE ASSISTÊNCIA TÉCNICA INTEGRAL (CATI). Programa Estadual de Microbacias Hidrográficas. Manual do Programa - Seção Operativa. CATI: São Paulo, 2001.

COORDENADORIA DE ASSISTÊNCIA TÉCNICA INTEGRAL (CATI). Disponível em < http://www.cati.agricultura.sp.gov.br/portal/imprensa/noticia/cati-realiza-o-iii-forum-consultivo-domicrobacias-ii-acesso-ao-mercado-e-produtores-rurais-mostram-como-transformaram-suas-vidas $>$ Acesso em 30/11/2018.

COORDENADORIA DE ASSISTÊNCIA TÉCNICA INTEGRAL (CATI). Disponível em < http://www.cdrs.sp.gov.br/microbacias2/o-projeto > Acesso em 14/04/2020.

COSTA, M. B. L. C da. As relações de trabalho, a máquina e o fato. Rev. Trib. Reg. Trab. $3^{\mathrm{a}}$ Reg; Belo Horizonte, v.51, n.81, p. 91-105, 2010.

CLEMENTE, E. C.; OLIVEIRA, A. R. de. O Programa Estadual de Microbacias no Estado de São Paulo: uma análise da descentralização administrativa e o incentivo ao associativismo por meio da FAMHESP. Caderno Prudentino de Geografia, Presidente Prudente, n.37, v.1, p.22-42, jan./jul. 2015.

DIÁRIO DO COMÉRCIO. Disponível em < https://dcomercio.com.br/categoria/inovacao/jundiaitem-a-primeira-vinicola-movel-do-pais $>$ Acesso em 21/09/2018.

HESPANHOL, A. N. Modernização da Agricultura e Desenvolvimento Territorial/ In: Encontro Nacional de Grupos de Pesquisa - ENGRUP, $4^{\circ}$., 2008, São Paulo. p. 370-392.

HESPANHOL, R. A. de M. O Programa de Aquisição de Alimentos: Limites e Potencialidade de Políticas de Segurança Alimentar para a Agricultura Familiar. Sociedade \& Natureza (UFU Online), v.25, p.469-483, 2013.

LAZZARI, F. M.; SOUZA, A. S. Revolução Verde: impactos sobre os conhecimentos tradicionais. In: Congresso Internacional de Direito e Contemporaneidade: Mídias e Direitos da Sociedade em Rede, 2017, Santa Maria. UFSM, 2017.

MATTEI, L. F. Evolução do crédito do PRONAF para as categorias A e A/C entre 2000 e 2010. Revista Econômica do Nordeste, v. 45, p. 58-69-69, 2014.

MELO, N. A. de. Economia Solidária e Mundo do Trabalho: possibilidades, limitações e contradições para o processo de desenvolvimento econômico. 1.ed. São Paulo: Editora Unesp, 2014, p. 200. 
MUMIC, B.; AGUIAR, K.A.P.; LIVRAMENTO, D. E. A IMPORTÂNCIA DO ASSOCIATIVISMO NA ORGANIZAÇÃO DE PRODUTORES RURAIS. REVISTA DE INICIAÇÃO CIENTÍFICA DA LIBERTAS, v. 5, p. 77, 2015.

NEVES NETO, C. de C. O Programa Estadual de Microbacias Hidrográficas em São Paulo: o caso do município de Assis/SP. Dissertação (Mestrado em Geografia). Faculdade de Ciências e Tecnologia, FCT/UNESP, Presidente Prudente. 196 f. 2009.

NEVES NETO, C. de C. Políticas Públicas \& Desenvolvimento Rural: o Programa de Microbacias I e II no Estado de São Paulo. Tese (doutorado em Geografia). Faculdade de Ciências e Tecnologia, FCT/UNESP, Presidente Prudente, 312 f, 2013.

NEVES NETO, C. de C. O Desenvolvimento Rural no Brasil e em Portugal: os casos do Programa de Microbacias em São Paulo e da Iniciativa Leader em Portugal. Rev. Ateliê Geográfico, GoiâniaGO, v.8, n.1, p. 74-102, abr/2014.

PREFEITURA MUNICIPAL DE JUNDIAÍ. Disponível em < https://jundiai.sp.gov.br/noticias/2016/05/24/cooperativa-de-vinho-e-pioneira-em-caminhaoenvasador/ > Acesso em: 15/09/2018.

PRIORI, A.; POMARI, L. R.; AMÂNCIO, S. M.; IPÓLITO, V. K. História do Paraná (Séculos XIX e XX). 1. ed. Maringá: Eduem, 2012. v. 1000. A modernização do campo e o êxodo rural. pp. 115127.

RIZZATOUR TURISMO. Disponível em $<$ https://www.rizzatour.com.br/circuito-das-frutas $>$ Acesso em: 28/04/2020.

SACCO ANJOS, F.; CALDAS, N. V. A propósito do debate sobre pluriatividade e multifuncionalidade na agricultura: o surgimento de uma nova formação discursiva. Revista Theomai/ Theomai Journaul, 2009.

SACCO DOS ANJOS, F; BECKER, C. Agricultura Familiar e Mercados Institucionais: O desenvolvimento como liberdade. Revista Econômica do Nordeste, v. 2014, p. 92-101, 2014

SÃO PAULO (Estado). Secretaria de Agricultura e Abastecimento e Secretaria do Meio Ambiente. Coordenadoria de Assistência Técnica Integral e Coordenadoria da Biodiversidade e Recursos Naturais. Projeto de Desenvolvimento Rural Sustentável. MICROBACIAS II - Acesso ao mercado. Anexo 1: Informações gerais da agropecuária do Estado de São Paulo, 2010 b.

SÃO PAULO (Estado). Secretaria de Agricultura e Abastecimento e Secretaria do Meio Ambiente. Coordenadoria de Assistência Técnica Integral (CATI) e Coordenadoria da Biodiversidade e Recursos Naturais. Projeto de Desenvolvimento Rural Sustentável. MICROBACIAS II Acesso ao mercado. Acordo de empréstimo - 7908 BR: Manual Operacional, 2015.

SILVA, R. F. G. As organizações coletivas no campo: análise do cooperativismo e do associativismo em Jataí e Rio Verde - GO. Dissertação (Mestrado em Geografia). Programa de Pós-Graduação da Universidade Federal de Goiás. p. 119, 2016. 
SILVEIRA, R.M. Disponível em < http://rogeriosilveira.jor.br/tag/coordenadoria-de-assistenciatecnica-integral-cati/page/5/ > Acesso em: 15/09/2018.

TEIXEIRA, Jodenir Calixto. Modernização da Agricultura no Brasil: Impactos Econômicos, Sociais e Ambientais. Revista Eletrônica da Associação dos Geógrafos Brasileiros, Três Lagos-MS, V 2 n 2, p. 21-42, Setembro/ 2005.

VEIGA, J.E. Agricultura familiar e sustentabilidade. In: Cadernos de Ciências e Tecnologia. Brasília: Embrapa. V. 13; n. 3; p. 383-399, 1996

VINHAES, A. S.; HESPANHOL, A. N.; ROCHA, T. R. DESCENTRALIZAÇÃO DE POLÍTICAS PÚBLICAS E A ATUAÇÃO DO MUNICÍPIO DE SÃO JOÃO DO PAU D' ALHO NA PROMOÇÃO DO DESENVOLVIMENTO RURAL. In: I Simpósio Nacional de Geografia e Gestão Territorial e XXXIV Semana de Geografia da Universidade Estadual de Londrina, 2018, Londrina. I Simpósio Nacional de Geografia e Gestão Territorial e XXXIV Semana de Geografia da Universidade Estadual de Londrina. Londrina, 2018. p. 1321-1332. 